\title{
【专题评述】
}

\section{壳-幔过渡带及其在岩石圈构 造演化中的地质意义}

\author{
邓万明钟大赛 \\ (中国科学院地质研究所, 北京 100029)
}

\section{关键词“壳-幔过渡带”青藏高原 钾质火山岩 岩石圈 造山带}

经典的地球物理学把地壳和上地幔之间的界面叫做莫霍面, 是根据地震波的速度在地壳 $\left(V_{\mathrm{P}}=5.8 \sim 6.5 \mathrm{~km} / \mathrm{s}\right)$ 和上地幔 $\left(V_{\mathrm{P}}=8.0 \sim 8.3 \mathrm{~km} / \mathrm{s}\right)$ 之间的不连续来定义的. 由于大陆岩石 圈结构的横向不均匀性,并不是所有地方的莫霍界面都十分清晰. 在一些地区的下地壳与上地 幔之间存在着一个 $\mathrm{P}$ 波速度的“递变层”或“过渡带”, 其 $V_{\mathrm{P}}$ 大约为 $6.8 \sim 7.8 \mathrm{~km} / \mathrm{s}$. 因此, 莫霍 界面不是那么清楚, 这是地震学家在岩石圈速度结构剖面研究中经常感到困惑的问题.

在青藏和滇西地区产出了一套富钾质的第三纪和第四纪的火山岩和浅成富碱斑岩，它们 在地球化学性质和同位素组成上独具特色, 是高原及邻区新生代以来岩石圈构造演化特定阶 段的产物。大量的证据表明, 上述岩浆活动与青藏的 “壳-幔过渡带”有密切关系。不仅如此, “壳-幔过渡带”的形成、部分熔融对陆内造山带的构造演化、矿床成因以及对青藏高原的近期 快速隆升也有显著的影响. 本文根据火山岩和斑岩的研究, 从地质学、岩石学、地球化学和地 球物理学等方面对“壳-幔过渡带”的特点、形成机制及其对板内造山带构造演化的地球动力学 意义进行初步探讨.

\section{1 “壳-幔过渡带”的实例及基本特征}

例 1 在阿尔卑斯地区(拉戈-拉戈雷附近)的下地壳底部存在着 $\mathrm{P}$ 波速度的异常。在该

57 Wang F Y. Ergodicity for infinite-dimensional diffusion processes on manifolds. Sci Sin, Ser A, 1994, 37(2): 137 146

58 Wang F Y. Uniqueness of Gibbs states and the $L^{2}$-convergence of infinite-dimensional reflecting diffusion processes. Sci Sin, Ser A, 1995, 38(8): 908 917

59 Wang F Y. Estimation of the first eigenvalue and the lattice Yang-Mills fields. Chin J Math, 1996, 17A(2): 147 154 (in Chinese); Chin J Contem Math, 1996, 17(2): 119 126(in English)

60 Chen M F. Optimal Markovian couplings and application to Riemannian geometry. In: Grigelionis B, et al, eds. Prob Theory and Math Stat, 1994, $121 \sim 142$

61 Chen M F. Trilogy of couplings and general formulas for lower bound of spectral gap. In: Accardi L, Heyde C, eds. Proceedings of the Symposium on Probability Towards the Year 2000, New York: Springer-Verlag, 1996, 337 360

62 Chen M F. Coupling, spectral gap and related topics ( I ), ( II ), ( III). Chin Sci Bull, 1997, 42(16): 1 321; 42(17): $1409 ; 42(18): 1479$

63 Djehiche B, Kaj I. The rate function for some measure-valued jump processes. Ann Prob, 1995, 23(3): $1414 \sim 1438$

64 Durrett R, Levin S. The importance of being discrete (and spatial). Theoret Pop Biol, 1994, 46: 363 394

65 Durrett R. Ten lectures on particle systems. St Flour Lecture Notes, LNM 1608, 1995

66 Durrett R, Neuhauser C. Particle systems and reaction-diffusion equations. Ann Prob, 1994, 22(1): 289 -333

(1997-04-29 收稿) 
区地壳厚度 (以 $V_{\mathrm{P}}$ 达到 $8.2 \mathrm{~km} / \mathrm{s}$ 的地幔深度为限) 为 $55 \mathrm{~km}$. 在 $30 \mathrm{~km}$ 以下 $V_{\mathrm{P}}$ 由 $6.6 \mathrm{~km} / \mathrm{s}$ 逐渐增大到 $8.2 \mathrm{~km} / \mathrm{s}$ (图 1), 其“过渡带”厚达 $25 \mathrm{~km}$, 速度梯度仅为 $0.068 \mathrm{~km} / \mathrm{s}$.

例 2 有的大陆地区不能严格地归属为“造山”的或“稳定”的单元, 而是处于一种过渡的 性质. 美国南部密苏里州 Girardeau 地区就是一个这样的例子, 该区存在一个 $V_{\mathrm{P}}$ 平均值为 $7.3 \mathrm{~km} / \mathrm{s}$ 的波速过渡带, 其厚度大约为 $18 \mathrm{~km}$, 速度梯度为 $0.1 \sim 0.08 \mathrm{~km} / \mathrm{s}$ (图 2).

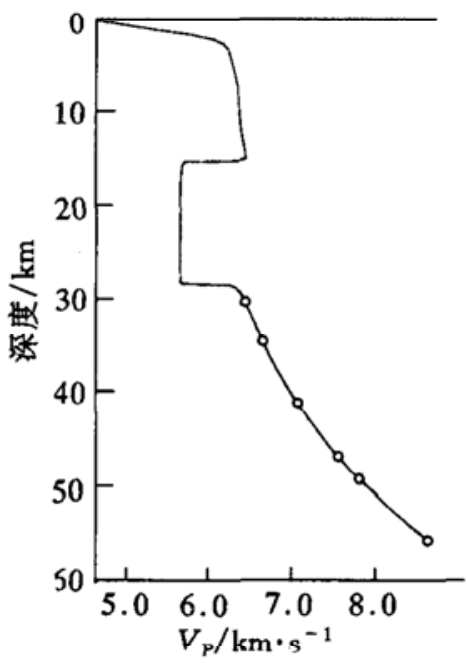

图 1 阿尔卑斯地区(拉戈-拉戈雷附近)P 波 速度-深度剖面图 ${ }^{[5]}$

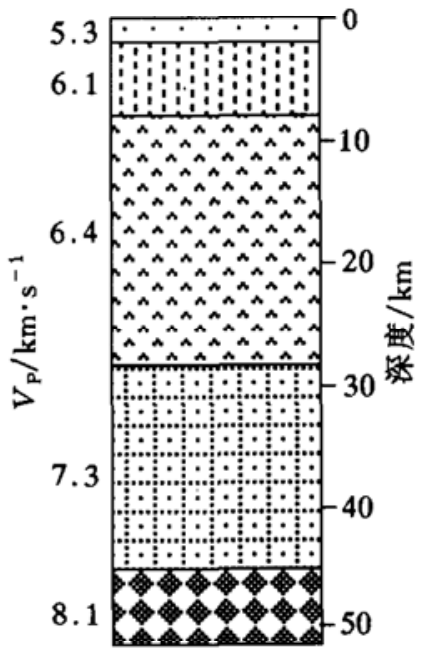

图 2 美国南部密西西比湾的地壳模式 ${ }^{[5]}$

例 3 根据西藏色林错至雅安多的深部地震测深和亚东至格尔木的地学大断面研究, 均 发现在青藏高原广泛发育波速为 $V_{\mathrm{P}}=7.36 \sim 7.42 \mathrm{~km} / \mathrm{s}$ 的波速过渡带 ${ }^{[1 \sim 3]}$ (图 3). 在当雄以 北这一层的厚度达到 $30 \mathrm{~km}$ (地震波速度随深度增加而递增, 平均为 $7.4 \mathrm{~km} / \mathrm{s}$ ), 是目前世界 上发现的最厚的地区. 最近吕庆田等用重力测量的资料, 也得出青藏高原的莫霍界面是一很 厚的“壳-幔混合层”的结论 ${ }^{[4]}$.

例 4 我国华北地区的波速过渡带是一个高波速梯度带, $V_{\mathrm{P}}=7.2 \sim 7.3 \mathrm{~km} / \mathrm{s}$, 在下降区 厚度仅 $2 \mathrm{~km}$ 左右, 而速度梯度比较高 $(0.2 \sim 0.4 \mathrm{~km} / \mathrm{s}$ ); 在相邻的山地 (上升区) 过渡带的厚度 增至 $5 \sim 6 \mathrm{~km}$, 速度梯度变小 $(0.05 \sim 0.1 \mathrm{~km} / \mathrm{s})$. 近年在我国安阳至泗水的地震剖面上也发 现了 $V_{\mathrm{P}}=7.2 \sim 8.0 \mathrm{~km} / \mathrm{s}$ 的速度过渡带, 厚度为 $5 \sim 10 \mathrm{~km}$ (图 4).

从实例和实验结果可得到“壳-幔过渡带”的基本地球物理学和物质成分的特性是：

(1) 在空间上“壳-幔过渡带”位于典型地壳层与上地幔层之间;

(2)对世界上大陆地区不同构造单元 90 多例折射剖面法的探测并结合大量的实验室内各 种岩石样品的波速测量结果发现 ${ }^{[7]}$, 在下地壳内有 $94 \%$ 的波速值落在 $6.4 \sim 7.4 \mathrm{~km} / \mathrm{s}$ 之间, 并存在 $6.7 \sim 6.8 \mathrm{~km} / \mathrm{s}$ 的高峰值和 $7.1 \sim 7.5 \mathrm{~km} / \mathrm{s}$ 的次高峰值. 在不同的构造环境这种双峰 式的速度分布相当普遍;

(3)下地壳内很宽的波速值在岩石组合上对应着从石英云母片岩、斜长角闪岩到酸性和中 性麻粒岩等, 71 75 km/s 的高峰值则对应于基性麻粒岩和榴辉岩;

（4）总的趋势是 $V_{\mathrm{P}}$ 随深度的加大波速值亦增加, 可以呈匀速递增、阶梯式递增、高-低速 带交错递增等情况, 反映了“过渡带”岩石组合和构造的复杂性; 


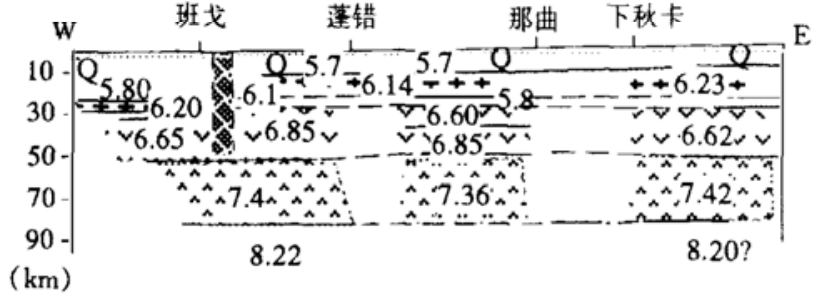

图 3 西藏班戈-下秋卡地震波速度结构图( 据文献[2]简化)

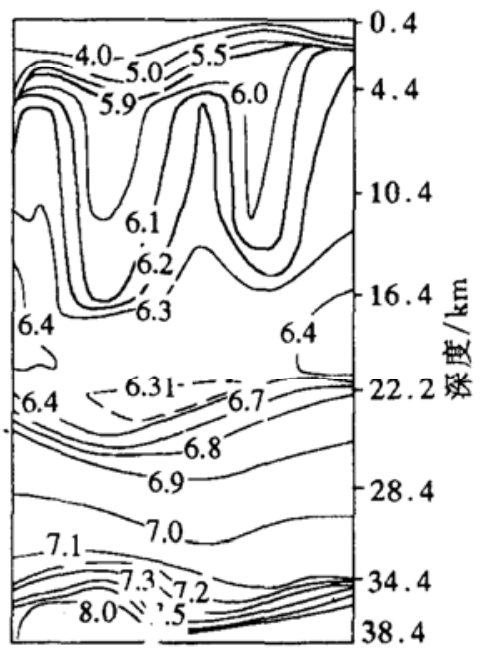

图 4 安阳至泗水的地震波反射剖面图 ${ }^{[6]}$

(5)“壳-幔过渡带”的厚度变化很大, 表明地壳的横向不均匀性是非常明显的. 在稳定的 地台区一般仅 $300 \sim 500 \mathrm{~m}$, 速度梯度高, 因而莫霍界面易于识别; 在古老造山带为 $2 \sim 5 \mathrm{~km}$, 在大陆裂谷带一般可达 $3 \sim 5 \mathrm{~km}$; 在年轻的陆内造山带“壳-幔过渡带”的厚度为 $10 \sim 20 \mathrm{~km}$, 在 高原隆起区为 $20 \sim 30 \mathrm{~km}$, 其波速梯度很小, 仅 $0.05 \sim 0.1 \mathrm{~km} / \mathrm{s}$; 那些处于稳定和活动单元之 间的地区“壳-幔过渡带”的厚度也介于中间数值;

(6)“壳-幔过渡带”的下界面即真正的地震莫霍面 $(M)$ ，在青藏以及一些年轻的造山带都 发现 $M$ 面并不是平直的, 而且还出现多处的错断和叠置. 如在雅鲁藏布缝合带的两侧 $M$ 面 垂直错距达 $10 \mathrm{~km}$, 呈一组断裂错移状彼此叠覆, 显示了下地壳与上地幔穿插与交错 ${ }^{[8]}$;

(7) 在大洋和边缘海盆地之下也测得 $V_{\mathrm{P}}=7.1 \sim 7.6 \mathrm{~km} / \mathrm{s}$ 的波速过渡带, 同样存在上、下 两个地震波的反射界面. 不过大陆与大洋的波速过渡带各有其特点, 可见在全球的岩石圈构 造模式中“壳-幔过渡带”的存在是一个相当普遍的客观事实.

\section{2 “壳-幔过渡带”的地质作用和物质组成}

在壳-幔边界的地质作用主要是物质成分和能量的交换. 比如部分熔融作用、矿物的重结 晶和物相转变、地幔熔体和流体的侵入、由于大陆碰撞导致的地壳断块的塌陷、加厚以及壳-幔 岩石和矿物的密度差引起的热力和重力的传导等. 在稳定的克拉通地区, P 波的双峰值可能 反映古老的基底经历了两阶段的地壳形成过程. 低峰值 $(6.7 \sim 6.8 \mathrm{~km} / \mathrm{s})$ 与岛弧区的波速值 接近, 表明其下地壳的形成与岛弧岩浆活动有关. 高峰值 $(7.1 \sim 7.3 \mathrm{~km} / \mathrm{s}$ )则可能是强烈的基 性岩和超基性岩的板下垫托作用 (Underplating)的结果, 或者与陆壳岩石俯冲到地幔引起的麻 粒岩相到榴辉岩相的高级深变质岩的形成有关，在大陆裂谷带和年轻造山带厚的“壳-幔过渡 带”, 以及高热流异常与上地幔甚至软流圈物质的上侵有密切的联系.

根据实验岩石学的研究和“壳-幔过渡带”波速随深度变化的事实, 证明过渡带本身具有成 层性, 即总的趋势是丽向深处岩石的基性度增加. 从岩石学的角度来看, 密度小的含水硅铝质 矿物逐渐被密度大的无水镁铁质矿物所替代, 从而出现更加基性的岩石. 在高温高压下可直 接测定各种岩石和矿物的波速, 由得到的岩石和造岩矿物的波速测定值与实测的地震波速度 反复拟合,就可以建立一个具体地区的“壳-幔过渡带”的岩石学模型. 笔者用文献 [9]提供的 
资料和方法,计算了一个年轻的造山带自中地壳下部至上地幔顶部的理想化的模型如表 1.

表 1 一个理想化的造山带“壳-幔过渡带”剖面(自上而下)

\begin{tabular}{|c|c|c|c|c|c|c|c|c|c|}
\hline 岩石 & Q & $\mathrm{Pl}$ & $\mathrm{Hb}$ & Gt & Cpx & Opx & $\mathrm{Ol}$ & $V_{\mathrm{P}} / \mathrm{km} \cdot \mathrm{s}^{-1}$ & $V_{\mathrm{S}} / \mathrm{km} \cdot \mathrm{s}^{-1}$ \\
\hline 角闪岩相片麻岩 & & & & & & & & $6.30 \sim 6.60$ & 3.75 \\
\hline 斜长角闪岩 & & 15 & 85 & & & & & 6.97 & $3.40 \sim 3.60$ \\
\hline 角闪岩 & & 5 & 95 & & & & & 7.02 & 3.80 \\
\hline 石榴石角闪岩 & & & 95 & 5 & & & & 7.11 & 3.86 \\
\hline 中性麻粒岩 & 5 & 40 & & 20 & 35 & & & 7.33 & 4.10 \\
\hline 基性麻粒岩 (A) & & 35 & & 10 & 25 & 30 & & 7.45 & 4.23 \\
\hline 基性麻粒岩(B) & & 22 & & 8 & 30 & 40 & & 7.57 & 4.37 \\
\hline 中性榴辉岩(A) & & & & 20 & 80 & & & 7.87 & 4.46 \\
\hline 中性榴辉岩(B) & & & & 30 & 70 & & & 7.95 & 4.49 \\
\hline 基性榴辉岩 & & & & 50 & 50 & & & 8.11 & 4.57 \\
\hline 方辉数桦岩 & & & & & & 20 & 80 & 8.22 & 4.60 \\
\hline
\end{tabular}

\section{3 青藏及滇西新生代钾质火山岩和富碱斑岩的对比及源区特征}

以雅鲁藏布蛇绿岩的侵位和缝合带的形成为标志, 在 $50 \mathrm{Ma}$ 以前的早第三纪青藏高原上 新特提斯洋最后封闭, 此后高原及邻区开始了以陆内变形和强烈隆升为特点的历史篇章. 在 高原北部发育了一套高钾质的第三纪火山岩 (南亚带) 和高钾钻碱质 + 钾玄质火山岩 (北亚 带 $)^{[10,11]}$. 据目前所掌握的资料, 这一期火山活动在古新世-始新世已经开始, 只是喷发的强 度和区域很有限. 自渐新世-中新世是本区火山活动的一个高峰, 这一阶段的火山岩遍及藏北 㒸塘腹地; 中新世以后至早更新世又出现一个小的高潮, 并且向北面的可可西里山和昆仑山推 进; 中晚更新世的火山活动已接近尾声, 主要集中在一些分散的剪切-拉张盆地中. 总的趋势 是南老北新, 在北西带东老西新.

在滇西沿金沙江-哀牢山缝合带也有一套新生代的富钾质的斑岩产出, 其时代大约在 25 ３5 Ma, 还有一些差不多同时代的侵入岩伴生. 这一期岩浆活动与藏北渐新世-中新世的高 峰期是对应的. 有的研究者主张金沙江岩带与藏北芫塘岩带是相连的, 在成因上认为是与一 条区域性的裂谷作用有关 ${ }^{[12,13]}$. 但近来的研究表明, 它们的成因涉及到在陆内变形体制下岩 石圈演化的一个相当复杂的地球动力学过程 ${ }^{[14]}$.

关于以上两个地区的火山岩和富碱斑岩都有大量的研究成果发表. 本文仅对与源区性质 有关的地球化学, 尤其是同位素组成方面的特点作一简要的对比. 这两个地区的岩石有很多 方面是相似的, 它们都形成在碰撞后的构造环境; 除西差塘个别时代较早的火山区 (如邦达 错、通天桥) 的岩石富钠外, 其他的岩区均以富钾 $\left(\mathrm{K}_{2} \mathrm{O}>\mathrm{Na}_{2} \mathrm{O}\right)$ 为特征; 两者都有 LILE 和 REE 的富集, 都不显示销的异常; 特别重要的是两个地区的岩石 $\mathrm{Sr}, \mathrm{Nd}$ 和 $\mathrm{Pb}$ 同位素成分均介于亏 损地幔和地壳端元之间的过渡位置 ${ }^{[11,14]}$. 不过藏北火山岩的 $\Sigma$ REE 丰度更高和 LREE 的富 集程度更强以及 $\mathrm{Sr}, \mathrm{Nd}$ 和 $\mathrm{Pb}$ 同位素比值的略有不同(表 2).

表 2 藏北和滇西新生代钾质火山岩和斑岩的同位素组成的对比(平均成分)

\begin{tabular}{lllllll}
\hline & $\left({ }^{87} \mathrm{Sr} /{ }^{86} \mathrm{Si}\right)_{i}$ & ${ }^{143} \mathrm{Nd} /{ }^{144} \mathrm{Nd}$ & $\varepsilon_{\mathrm{Nd}}(T)$ & ${ }^{206} \mathrm{~Pb} /{ }^{204} \mathrm{~Pb}$ & ${ }^{207} \mathrm{~Pb} /{ }^{204} \mathrm{~Pb}$ & ${ }^{208} \mathrm{~Pb} /{ }^{204} \mathrm{~Pb}$ \\
\hline 藏北(北) & $0.7089(24)$ & $0.5123(24)$ & $-6.6(24)$ & $18.7270(9)$ & $15.6820(9)$ & $39.0340(9)$ \\
藏北(南) & $0.7056(4)$ & $0.5126(4)$ & $\approx 0(4)$ & $18.5750(4)$ & $15.6200(4)$ & $38.9900(4)$ \\
滇西 & $0.7070(8)$ & $0.5124(8)$ & $-4.6(8)$ & $18.6037(8)$ & $15.6337(8)$ & $38.7571(8)$ \\
\hline
\end{tabular}

a) 根据文献 $[11,14,15]$ 和部分未发表的资料计算, 括号内为样品数 
根据两个地区成因岩石学的系统研究, 我们认为它们都是来源于“壳-幔过渡带”的部分熔 融. 无论是藏北或滇西大多数岩石属中性岩, 成分上相当于富钾玄武安山质岩浆系列, 它们不 但富有中酸性岩特征的大离子亲石元素,而且一些在幔源岩石中富集的过渡金属元素也有相 当的富集. 这些岩石的轻稀土元素富集的分配型式无铺的负异常,说明成岩岩浆并不是幔源 玄武岩浆在基性斜长石分异作用后的残余熔体。这一重要特征无疑指示源区不是直接来自地 幔, 两区岩石的 $\mathrm{Sr}, \mathrm{Nd}$ 和 $\mathrm{Pb}$ 同位素组成, 均介于典型亏损地幔和陆壳之间的过渡位置。在两 区岩石中都发现了中、下地壳的变质岩包体, 如花岗片麻岩、大理岩、斜长角闪片麻岩、石榴石 角闪岩等. 在昆仑山和可可西里地区都多次发现火山岩中含有铁铝榴石、尖晶石、矽线石、刚 玉等变质矿物的捕虏晶 ${ }^{[16]}$, 它们代表了㒸塘板块和扬子板块的变质基底. 但到目前为止尚 未发现真正的地幔岩 (如方辉橄榄岩、二辉橄榄岩、纯檄榄岩等) 和高压榴辉岩的包体, 这就支 持岩浆源可能处于下地壳以下和上地幔顶部之间的位置, 即“壳-幔过渡带”的中、下部.

在 Sr-Nd 同位素蛛网图上尽管它们均处于壳-幔两个端元之间, 但藏北新生代火山岩的投影 点更稍偏向于地壳端元一侧, 而滇西富碱斑岩稍偏向于地幔端元的组成. 换言之, 前者源区地壳 的组分所占的份额略大, 后者相反。这些特点与藏北厚的“壳-幔过渡带” (通常达到 $20 \sim 30 \mathrm{~km}$ )、 稍低的波速值(7.38 7.42 km/s) 以及滇西 “壳-幔过渡带”的厚度通常只有 $10 \mathrm{~km}$ 左右, 波速达 $7.70 \sim 7.80 \mathrm{~km} / \mathrm{s}$ 是相对应的 ${ }^{[17]}$, 有理由推断, 藏北火山岩可能来自于中性-基性麻粒岩层, 而滇 西岩石可能来源于基性麻粒岩-中性榴辉岩的部分熔融, 即后者源区的深度更大.

\section{4 大洋岩石圈的“売-幔过渡带”:来自蛇绿岩的启示}

按照板块构造的观点, 一套由镁铁质和超镁铁质岩组成的蛇绿岩套是过去大洋岩石圈存 在的证据, 在大洋封闭后作为碎片残留在缝合带中. 由于构造侵位以及造山后的破坏, 这些岩 石大都呈蛇绿混杂岩块的形式产出,但在某些地段依然部分地或较多地保留了它的原始假层 序结构. 对特罗多斯、阿曼、纽芬兰以及我国雅鲁藏布蛇绿岩带等的深入研究, 已经能够重建 它的原始层序性(图 5). 另一方面, 对海洋大量的地震折射研究, 证明大洋地壳具简单的层状

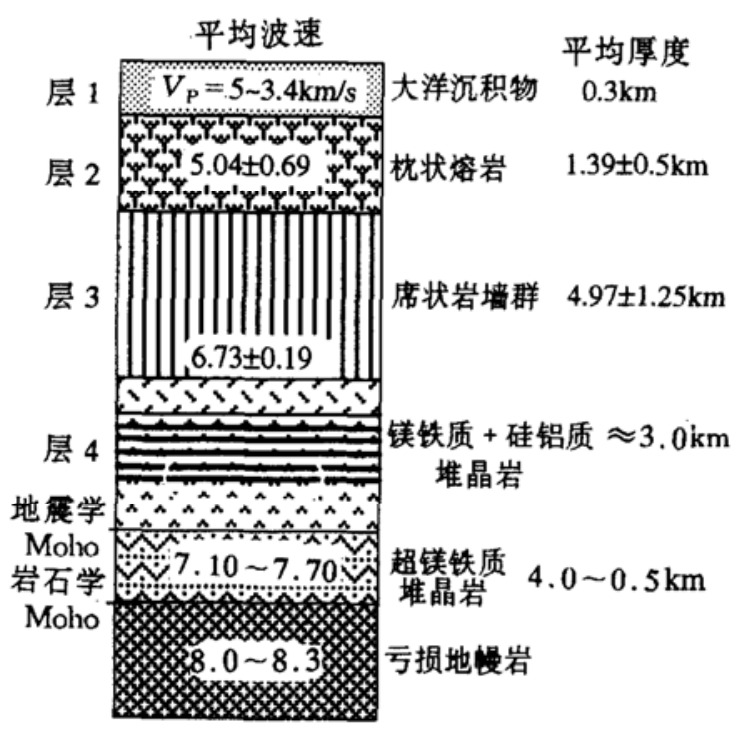

图 5 -个理想化的蛇绿岩层序构造 ${ }^{[18]}$
结构. 这种结构与陆地上的蛇绿岩的层序构造 有很多明显的相似性, 对于此两者的关系曾有 过剧烈的争论 ${ }^{[18]}$ 。尽管蛇绿岩的成因问题目 前在学术界还存在不少的分歧, 对于蛇绿岩是 形成在海洋环境, 它的原生剖面与大洋岩石圈 基本上可以对比的看法已不存在原则上的争 议。它们在许多方面惊人的相似性曾在地学界 引起了极大的轰动. 我们最感兴趣的是其中的 第 4 层, 它是由超镁铁质-镁铁质-硅铝质的一 套堆晶杂岩所组成, 堆晶杂岩的上部进入上覆 的辉绿岩 (岩墙群), 而底部不整合在大洋地幔 的变质檄榄岩之上. 堆晶杂岩本身可分为上部 的镁铁质 + 硅铝质堆晶杂岩和下部的超镁铁质 堆晶杂岩 (或称为临界带 ${ }^{[19]}$ 、过渡带) 两段。两 
者的界面叫做地球物理学莫霍面. 堆晶杂岩底部与变质橄榄岩的界面是岩石学的莫霍面,蛇 绿岩中堆晶超镁铁岩的厚度变化在 $4.0 \sim 0.5 \mathrm{~km}$, 由于构造加厚或低角度的逆冲都会影响厚 度的精确测定. 在太平洋的不同区域内都存在着 $V_{\mathrm{P}}=7.10 \sim 7.70 \mathrm{~km} / \mathrm{s}$ 的异常高速带, 无论 是大洋岩石圈的 3 层或 4 层模式, 都可以看到一个 $7.10 \sim 7.70 \mathrm{~km} / \mathrm{s}$ 或 $6.4 \sim 7.7 \mathrm{~km} / \mathrm{s}$ 的杂 岩带 ${ }^{[20]}$. 这一层与上部和下部成员之间有非常显著的差别, 从它的岩石组合、结构、岩石-地 球化学特点, 在剖面上的位置和 $V_{\mathrm{P}}$ 来看, 应该属于大洋岩石圈的“壳-幔过渡带”。大陆岩石 圈和大洋岩石圈“壳-幔过渡带”的共同特点是: 都位于壳-幔边界之间、 $V_{\mathrm{P}}$ 速度近似、随深度的 增加波速递增等。

\section{5 “壳-幔过渡带”与成矿作用}

板块构造论在成矿作用方面也为我们开创了新的思路. 在活动大陆边缘最典型的例子就是 所谓“斑岩型(铜、钼)”矿床的成因,这一类矿产无一例外的是出露在 B 型俯冲带的岛弧-陆缘一 侧. 在成因上与多期多阶段侵入的石英二长斑岩、花岗斑岩、石英闪长岩等有密切的关系, 成矿 母岩主要是来自钻碱性系列的一套安山质岩浆. Sillitoe ${ }^{[21]}$ 认为, 上述斑岩铜、钼矿床与大洋岩石 圈板块向大陆板块俯冲、部分熔融而形成的钙碱质岩浆有成因联系. $\mathrm{Cu}, \mathrm{Mo}$ 和 $\mathrm{Pb}$ 等多种金属元 素是来自于俯冲的大洋壳(第 $2 、 3$ 层), 这种观点得到了 $\mathrm{Rb}-\mathrm{Sr}, \mathrm{Pb}, \mathrm{O}$ 和 $\mathrm{H}$ 等同位素证据的支持. 据中国东部斑岩型铜、钼矿床的研究 ${ }^{[22]}$, 成矿的安山质岩浆本质上是洋壳物质混入了一些远洋 沉积物甚至地幔物质, 在很高的压力和约 $1200 \sim 1250^{\circ} \mathrm{C}$ 并有足够水参与下部分熔融的产物, 它 们的 $\delta^{18} \mathrm{O}(\%)$ 值变化在 $+5.7 \sim+10.2$ 之间, 峰值位于 $+7.5 \sim+10$, 正好介于幔源和壳源岩浆 的界线之间,因此叫作幔、壳混熔岩浆( MC 型)。多金属矿床的成因, 可以用库拉板块在中生代向 欧亚板块下俯冲的模式解释 ${ }^{[23,24]}$. 很可能俯冲板块下插入地幔楔引起壳、幔物质发生混合作用 形成的 “壳-幔过渡带” 是成矿物质的重要源区. 有大量的地球化学资料证明, 大洋壳中的 $\mathrm{Cu}$, $\mathrm{Mo}$ 和 $\mathrm{Au}$ 都有很高的丰度. 例如, 大西洋和太平洋中的玄武岩中平均含 $\mathrm{Cu}$ 为 $77\left(\mu \mathrm{g} \cdot \mathrm{g}^{-1}\right)$. 东 太平洋洋隆翼部沉积物中平均含 $\mathrm{Cu}$ 和 $\mathrm{Mo}$ 分别为 $990\left(\mu \mathrm{g} \cdot \mathrm{g}^{-1}\right)$ 和 $100\left(\mu \mathrm{g} \cdot \mathrm{g}^{-1}\right)$. 洋底锰结核含 $\mathrm{Cu}$ 高达 $2.5 \%$. 在太平洋粘土中 $\mathrm{Cu}$ 的平均丰度为 $323\left(\mu \mathrm{g} \cdot \mathrm{g}^{-1}\right), \mathrm{Mo}$ 为 $18\left(\mu \mathrm{g} \cdot \mathrm{g}^{-1}\right)^{[21]}$. 上述值 远远超出了上地幔和大陆壳 $\mathrm{Cu}$ 和 $\mathrm{Mo}$ 的丰度. 所谓“块状硫化物”矿床和层状、豆荚状 $\mathrm{Cr}$ 矿床 本身就是大洋岩石圈(蛇绿岩)重要的伴生物. 可以设想, 由于镁铁质洋壳 + 地壳沉积物与超镁 铁岩之间在化学成分和同位素组成上的极不相容, 在适当高的温、压和有水参与的条件下, 必然 会出现强烈的化学反应. 成矿元素 (如 $\mathrm{W}, \mathrm{Sn}, \mathrm{Mo}, \mathrm{Cu}, \mathrm{Au}, \mathrm{Pb}$ 和 REE 等) 大都不是亲石元素, 它们很难进入造岩矿物的晶格构造. 一旦有合适的构造和物理化学条件, 就能很快地从游离状 聚集为成矿母液. 西藏的冈底斯岛弧杂岩带和藏东、三江地区是我国重要的大型和超大型斑岩 型多金属成矿带. 研究它们的成因及其与“壳-幔过渡带”和造山带岩石圈演化的关系, 不但有重 要的科学意义,并将为指导找矿提供依据.

\section{6 “壳-幔混合层”形成机制的探讨}

岩石学家将地震学上的“壳-幔过渡带”称为“壳-幔混合层”(Crust-mantle mixed layer), 也 有的称为 “异常 (富集)地幔”。普遍认为这种源区是地壳物质与地幔岩发生了混合作用的结 果, 但其细节尚不清楚. 从上述 “壳-幔混合层”的复杂性很难有一个统一的成因模式. 根据目 前的认识, 初步考虑可能有 $\mathrm{B}$ 型俯冲伴随陆内 $\mathrm{A}$ 型俯冲 $(\mathrm{B}+\mathrm{A})$ 、岩浆结晶分异作用 $(\mathrm{MFC})$ 、 
软流圈上涌-板下垫托(UAU)等三种基本方式.

对藏北新生代钾质火山岩和滇西富碱斑岩的研究, 表明它的成因与某次造山事件的密切 联系. 含放射性成因 $\mathrm{Pb}$ 的矿物年龄大约是 $230 \sim 250 \mathrm{Ma}^{[14]}$. 藏北和滇西大地构造演化中发 生于晚二叠世到早三叠世的以可可西里-金沙江缝合带的形成为标志的碰撞造山事件正好与 $230 \sim 250 \mathrm{Ma}$ 相对应. 我们有理由推论, 在古特提斯洋的消减过程中可能有一部分被海水润 湿的大洋沉积物、海沟的陆源物质等随着大洋板块的俯冲作用被带到了地幔楔内, 并与增生楔 上部的地幔物质发生了深部的混合作用. 经过一段时间的均一化之后, 在下部地壳与亏损地 幔之间, 逐渐形成兼有两个端元特性的地球化学 “富集层”. Zindler 和 Hart ${ }^{[25]}$ 在总结南半球 的同位素异常特征时提出了 DMM( 亏损 MORB 地幔)、EM I (富集 I 型地幔)、EM II (富集 II 型地幔) 和 HIMU(高的 U/Pb) 4 种地幔端元类型. 在讨论 EM II 型时 Hart 指出, 它的最突出 的特征是有高 ${ }^{87} \mathrm{Sr} /{ }^{86} \mathrm{Sr}$, 最一般的模式认为它是俯冲带的大陆物质进入上地幔再循环的结果. 因为大陆沉积物的同位素特征对于 EM II 的形成是最为理想 $\left({ }^{87} \mathrm{Sr} /{ }^{86} \mathrm{Sr}>0.710,{ }^{143} \mathrm{Nd} /{ }^{144} \mathrm{Nd}\right.$ $<0.5120,{ }^{206} \mathrm{~Pb} /{ }^{204} \mathrm{~Pb}$ 的最小范围是 $15.8 \sim 19.2$ ), 同时也是由于在岛弧区消减带俯冲的沉 积物与岛弧熔岩的混染极其强烈, 因此, 弧火山岩与 EM II 的大洋玄武岩之间存在紧密的亲缘 关系 ${ }^{[26]}$. 藏北火山岩的 $\mathrm{Sr}, \mathrm{Nd}$ 和 $\mathrm{Pb}$ 同位素几乎都落在标准的 $\mathrm{EM} I I$ 范围内 ${ }^{[11]}$; 滇西富碱斑 岩的这些同位素成分也大都处于 EM II 的周围或稍偏向于 DMM 方向 ${ }^{[15]}$, 说明这两者的源区 大体上都有 EM II 地幔源的印记. 青藏高原及相邻的滇西地区是由若干个陆块在不同时期相 继拼接而成, 从北到南有好几条古俯冲带横贯东 西或北西 南东. 我们设想, 该区的“壳-幔 混合层”的形成可能经历了两个主要的过程:第一阶段即每一条古俯冲带及其邻近的壳、幔区 内都将形成一定规模的 EM II 型的异常地球化学“域”;第二阶段在新特提斯封闭之后, 在高原 地壳和岩石圈大幅度缩短和加厚的第三纪时, 那些相对孤立和分散的“域”才逐渐连通成“层”。 如果这一机制是合理的, 那么就不难理解为什么滇西富碱斑岩在岩石地球化学性质上与江达 弧火山岩有许多相似之处 ${ }^{[27]}$. 因为增生楔上部含水的熔体一部分以 CA 系列熔岩形式喷发 在活动大陆边缘的岛弧环境, 另一部分滞留在源区, 两者本来就有同源性, 这种 B+A 机制可 能适用于解释大陆碰撞造山带“壳-幔混合层”的成因.

大多数岩石学家, 赞同一套超镁铁质堆晶岩为成分的大洋岩石圈板块的 “壳-幔混合层” 是 幔源岩浆结晶分异作用成因. 蛇绿岩中超镁铁质堆晶杂岩, 以缺少变形组构和因岩石类型及 矿物成分的变化而出现的层状构造区别于变质橄榄岩. 这一转变带标志着从堆晶檄榄岩向堆 晶辉长岩的过渡, 通常表示橄榄石和辉石共生关系的结束. 换言之, 矿物共生组合由堆晶橄长 岩或檄榄岩的 $\mathrm{Ol}+\mathrm{Pl}, \mathrm{Ol}+\mathrm{Opx}+\mathrm{Cpx}$ 逐渐转变为辉长岩的 $\mathrm{Cpx}+\mathrm{Pl}$, 转变带之上无檄榄岩而 以辉长岩占优势. 总之, 大量的岩石学、地球化学和同位素证据证明, 蛇绿岩的堆晶岩部分是 幔源拉斑玄武岩浆在岩浆室中的结晶分异作用的产物. 岩浆室的厚度及发育又主要取决于洋 脊的扩张速度. 一般看来, 在快速扩张洋脊和开放系统下可形成较厚的“壳-幔混合层”, 相反 则较薄. 对大洋“壳-幔混合层”的这些初步认识, 主要是根据蛇绿岩的研究结果. 众所周知, 蛇绿岩仅仅是被消减掉的大洋岩石圈板块残留的极少部分. 全球大洋岩石圈板块的分层细节 人们还所知甚少, 除了地震波的资料外, 大洋钻探尚未达到堆晶杂岩的深度, 大洋岩石圈“壳幔混合层”的特性及其形成机制还有待深入研究.

“壳-幔混合层”形成的第 3 种可能的模式, 即所谓因软流圈物质上涌而导致岩浆的板下 “热垫托作用” (Thermal underplating), 也就是上地幔和下地壳物质在来自深部熔体的热力作 
用下生成了混合岩浆, 这种模式可能适用于稳定区的比较年轻的裂谷带或造山带碰撞后期的 情况. 至于是什么机制使得软流圈物质上侵并造成了哪些地质效应, 目前已经提出了一些假 说, 如岩石圈的伸展、下岩石圈地幔的拆沉(Delamination)、板片裂离 (Slab break off)等. 这是 目前大陆造山带研究的一个热门话题, 我们将在下面讨论.

\section{7 “壳-幔混合层”的部分熔融与板内变形和高原隆升的关系}

青藏高原及邻区在早第三纪进入了构造转换和大调整的时期. 在印度板块、塔里木和扬子 板块的多向挤压下, 岩石圈受到大幅度的缩短、加厚和抬升. 同时伴随了强烈的陆内俯冲、走滑 和伸展变形. 根据 70 年代以来的地球物理研究揭示, 青藏高原的岩石圈厚度在南部分仅仅只有 90 120 km, 北部为 $120 \sim 140 \mathrm{~km}$, 其地壳厚度大约是印度地壳的两倍, 然而青藏高原的岩石圈 厚度仅相当于印度地盾岩石圈的 $3 / 5^{[28]}$. 因此, 高原总体上呈现出上部是热而轻的厚地壳 $(60 \sim$ $80 \mathrm{~km}$ ), 下部是重而薄的上地幔 $(40 \sim 60 \mathrm{~km})$. 这种不协调的壳-幔结构不是固有的和不变的, 而 是岩石圈长期演化的一个结果. 已经提出了好几种理论模式来探讨高原及邻区岩石圈缩短和加 厚的几何学和动力学机制, 这里不作评述. 只强调一点, 加厚了的岩石圈地幔必然在重力、热力 和物质组成上都是不稳定的. 经粗略的估算, 要在有限的时限内使 $250 \mathrm{~km}$ 厚的岩石圈板块减薄 到现在的厚度仅仅归因于软流圈的热熔融是有困难的. 因此, 岩石圈板块底部的构造剥离 (Delamination or Decollement 或称滑税、拆沉等) 或平流减薄 (Advective thinning)似乎更为合理, 即一部 分物质从岩石圈地幔底部剥离下来并坠入更深的地幔或软流圈中. 近年的地震层析 (CT) 方法, 为寻找地幔内拆沉的冷岩石圈块体提供了可能. Maruyama(1994) 把东亚大陆下面 $400 \sim 800 \mathrm{~km}$ 范围内的 ( $V_{\mathrm{P}}$ 高速异常) 硬块, 均看着是俯冲大洋岩石圈板块剥离出来并堆积在 $670 \mathrm{~km}$ 界面附 近的巨大的岩石体 (Megaliths) ${ }^{[29]}$. 岩石圈板块底部的构造剥离作用, 将导致一系列重要的深部 地质过程. 由于冷而重的岩石圈块体的剥落必将引起岩石圈上部因重力均衡产生反向的回弹效 应, 这可能是高原快速抬升以及发生在兴都库什等地的深源地震的原因. 此外, 软流圈的物质为 了填补亏损的空间, 势必向压力降低的方向运动和上侵, 致使残留岩石圈底部遭受到热侵蚀, 并 诱发“壳-幔混合层”的部分熔融. 我们曾将岩浆形成的这种方式叫做“滑脱补偿熔融”[30,31], 因 此, 藏北及滇西的新生代火山作用和斑岩的成因直接受板内变形构造的控制. 它们是新生代以 来岩石圈构造演化到一定阶段的必然产物. 青藏高原的抬升, 尤其是 $3 \mathrm{Ma}$ 以来的快速抬升可能 是受多种因素综合作用的结果. 我们相信软流圈物质的上涌和 “壳-幔混合层”的部分熔融等热 力作用也作出了不容忽视的贡献.

在 80 年代初的中法喜马拉雅合作考察期间, 对那曲地区一条人工地震测深剖面的解释, 在地球物理学家中间曾有过一些争议. 他们感到困惑的是: 莫霍面究竟是处在上反射面还是 下反射面,如何理解一个“高速下地壳”或“低速上地幔”的存在. 面对厚达 $20 \sim 30 \mathrm{~km}$ 的“波 速异常带”, “非此即彼”的思维方式遇到了困难. 原因就在于对这样一种客观事实过去有所忽 略, 还因为在青藏高原上莫霍面本来就不是一个简单的“界面”而是具有一定厚度的“层”,这一 特点比世界其他地区更为突出. 目前“壳-幔过渡带”或“壳-幔混合层”的概念已逐渐被人们所 认识和接受, 因此对“壳-幔混合层”应该予以足够的重视. 当其厚度相当大的情况下 (比如 $\approx$ $10 \mathrm{~km}$ ) 以一个“层单元”独立出来并加以认真研究可能是有积极的意义.

致谢 本工作为国家自然科学基金(批准号: 49472102, 49232030)资助项目. 


\section{参考文献}

1 黄立言, 卢德源, 李小腸, 等. 藏北色林错-雅安多地带的深部地霞测深. 见: 中国地质科学院主编, 西藏地球物理文集. 北京: 地质出版社, 1990. 25 37

2 肖序常, 李廷栋, 李光岑, 等. 喜马拉雅岩石圈构造演化总论. 北京: 地质出版社, 1988.141 159

3 吴功建, 肖序常, 李廷栋. 青藏高原亚东-格尔木地学断面. 地质学报, 1989, (4):285 296

4 吕灰田, 姜 枚, 高 锐. 青藏高原莫垔面形态的重力模拟及其对探讨高原隆升机制的意义. 地球学报, 1997, 18(1): 78 86

5 Ringwood A E. Composition and petrology of the earth mantle. New York: McGraw-Hill, Inc, 1975. $30 \sim 32$

6 Lin Ge, Fan Weiming. The Crust-mantle transition zone and its geological processes. In: Pang Z H, et al. ed. Advances in Solid Eargh Science, Beijing: Science Press, 1996. 50 54

7 Holbrook W S, Mooney W D, Chriatensen N I. The seismic velocity structure of the deep continental crust. In: Continental Lower Crust. Developments in Geotectonics, 1992, 23:1 44

8 李廷栋, 吴功建, 肖序常. 青藏高原岩石圈构造及其演化特点的再认识. 见: 中国青藏高原研究会编, 青藏高原与全球 变化研讨会文集. 北京:气象出版社, 1995. 200 208

9 邓晋福, 吴宗絮, 杨建军, 等. 格尔木-额济纳旗地学断面走廊域地壳-上地撗岩石学结构与深部过程. 地球物理学报, 1995, 38(增刊): $130 \sim 143$

10 邓万明．西藏阿里北部的新生代火山岩一一兼论陆内俯冲作用。岩石学报, 1989, (3)：1１1

11 邓万明. 青藏北部新生代钾质火山岩微量元素和 Sr、Nd 同位素地球化学研究. 岩石学报, 1993，19(4):379 387

12 张玉泉, 谢应雯, 涂光炽, 等. 哀牢山-金沙江富碱侵入岩及其与裂谷构造关系初步研究. 岩石学报, 1987, 2(1): 17 28

13 张玉泉, 谢应雯, 涂光炽, 等. 横断山区花岗岩类地球化学. 北京: 科学出版社, 1995. 1 186

14 邓万明, 黄 萓, 钟大黄. 滇西金沙江带北段的富碱斑岩及其与板内变形的关系. 中国科学, D 辑, 1998, 28(1): 出版中

15 Arnaud $\mathrm{N} \mathrm{O}$, Vidal $\mathrm{Ph}$, Tapponnier $\mathrm{P}$, et al. The high- $\mathrm{K}_{2} \mathrm{O}$ volcanism of northwestern Tibet: geochemistry and tectonic implications. Earth Planet Sci Lett, 1992, 111: 351 367

16 邓万明, 郑锡澜, 松本征夫. 青海可可西里地区新生代火山岩的岩石特征与时代. 岩石矿物学杂志, 1996, 15(4): 289 298

17 高名修, 网荣举, 郑剑东, 等. 中国川滇西部岩石圈结构与喜马拉雅运动. 见: 中国科学院地质研究所岩石圈构造演化 开放实验室年报(1989 1990). 北京: 中国科学技术出版社, 1991. 49 53

Coleman R G. Ophiolites, Ancient Ocenaic Lithosphre? Berlin, Heidelberg, New York: Springer-Verlag, 1977. 1 16 Smith C H. Bay of islands igeous complex, western new foundland. Geol Survey Can Mem, 1958, 290: 1 132 $57 \sim 86$

21 Silltoe R H. A plate tectonic model for the origin of the porphyry copper deposits. Econ Geol, 1972, 67: 184 197

22 吴利仁,李秉伦。中国东部中生代两大类型斑岩型铜矿。北京: 科学出版社, 1991。1 2

23 吴利仁(主编)。华东及邻区中、新生代火山岩. 北京: 科学出版社, 1990. 1 287 吴利仁．中国东部中生代花岗岩类及两大斑岩矿床成因类型. 地质科学, 1988, (4):313 323

Zindler A, Hart S R. Chemical geodynanics. Annu Rev Earth Planet Sci, 1986, 14: 493 571 1988, A327: $379 \sim 413$

29 邓晋福, 赵海玲, 莫宣学, 等. 中国大陆根-柱构造一大陆动力学的钥匙. 北京: 地质出版社, 1996. 75 76

30 Deng Wanming. Cenozoic volcanism and intraplate subduction in northern margin of the Tibetan Plateau. Chinese J of Geochem, 1993, 10(2): 140 152

31 Deng Wanming. Decollement compensation melting - a formation model of magmas during A-type-subduction (as exemplified by the Quaternary volcanism in north Tibet). In: Advances in Geascience (2). Beijing: China Ocean Press, 1992. 140 144 